\title{
A.PORTES TEÓRICO-METODOLÓGICOS PARA O ESTUDO DE REDES TRANSNACIONAIS DE LÍDERES PENIECOSTAIS E CARISMÁTICOS
}

\section{Daniel Alves \\ Universidade Federal de Goiás - Brasil}

Resumo: O presente trabalho busca fornecer fundamentação teórico-metodológica ao conceito de rede aplicado ao estudo do pentecostalismo. Para tanto, abordarei os métodos de pesquisa associados ao estudo de redes e suas contribuições mais recentes. Num primeiro momento, nas décadas de 1950 e 1960, desenvolveu-se no campo da antropologia uma abordagem empiricista centrada na descrição e análise de relações observáveis dentro de um território limitado. No momento atual, diálogos com a história das ciências, a filosofia e a geografia permitem-nos repensar as redes num quadro teórico amplo, como lócus privilegiado do sincretismo e de novas formas de territorialidade. A análise de processos de transnacionalização religiosa pentecostal ao sul da América Latina pode se beneficiar da ancoragem teórica fornecida por essas discussões.

Palavras-chave: América Latina, pentecostalismo, redes, transnacionalização.

Abstract: The present article aims to provide theoretical and methodological basis to the concept of network applied to the study of Pentecostalism. Therefore, I will describe synthetically the research methods associated to network studies and their recent developments. In a first moment, along the 50' and the 60', it was unfolded an empirical approach based on description and analysis of observable relations on a limited territory. Currently, dialogues with History of Science, Philosophy and Geography allow us to rethink networks in a wide-range scope, as a privileged locus in which we can study syncretism and new forms of territoriality. The analysis of transnational religious processes at Southern Latin America could be improved by the theoretical anchorage offered by these discussions.

Keywords: Latin America, networks, Pentecostalism, transnationalization. 
A noção de rede, assim como a de sistema, estrutura e campo, perpassa o campo das ciências desde as experimentais, passando pelas aplicadas até as humanas. Nestas últimas, encontramos alguma diversidade nos usos desse termo. Cada sentido que essa noção adquire reflete os pressupostos teóricoepistemológicos de seu uso. Neste trabalho, faço nas proximidades de minha posição como antropólogo um mapeamento das variações dos estudos sobre redes, apontando a sua aplicabilidade em um projeto de pesquisa sobre a transnacionalização neopentecostal no Mercosul.

Desde seu surgimento como área acadêmica, no fim do século XIX e início do século XX, as ciências sociais comumente munem-se com aparatos conceituais oriundos, ou mesmo inspirados, nos artefatos analíticos das Naturwissenchaften. A ideia de evolução, advinda das ciências biológicas, foi fundamental para o primeiro projeto disciplinar da antropologia (Stocking, Jr., 1982). Os conceitos de sistema e função social foram transpostos desde a biologia para a sociologia positiva de Auguste Comte, consolidada depois em seu método por Émile Durkheim (1984, 2002). O estruturalismo de LéviStrauss dependia essencialmente de um conceito análogo ao que foi desenvolvido tanto nas ciências biológicas como nas exatas. Foi com matemáticos que o antropólogo francês desenvolveu os modelos da parte hard de As estruturas elementares do parentesco (Lévi-Strauss, 1982).

No terreno da antropologia, em meados dos anos 1950 nos Estados Unidos e na Inglaterra houve uma rejeição aos modelos formais do estruturalfuncionalismo, desenvolvidos em suas bases teóricas por Alfred RadcliffeBrown, e a primeira consolidação dos estudos de redes sociais. Houve um verdadeiro boom na utilização do método entre as décadas de 1950 e 1960; fazer uma resenha bibliográfica sobre o estudo de redes já era uma tarefa trabalhosa na década de 1970 (Jeremy Boissevain, em 1979, contabilizava mais de mil artigos já publicados sobre o tema). Hoje os estudos sobre rede estão de novo em voga, associados à problemática geral da globalização.

Por isso, dentro do campo de discussão que me é mais familiar, restringir-me-ei a três eixos, e desenvolverei cada um deles numa parte do trabalho. O primeiro, já anunciado, é o eixo da tradição antropológica e suas derivações. O segundo eixo desenvolver-se-á em diálogo com as teorias da globalização, e o terceiro, a partir da posição de Bruno Latour, contribuição mais recente que agrega a tradição antropológica empiricista ao campo conceitual mais in- 
fluenciado pelo giro linguístico pelo qual passaram as ciências humanas nas últimas décadas.

Sempre ao fim de cada tópico, procurarei transpor a discussão teórica para dar inteligibilidade a minha situação de campo. Minha pesquisa desenvolveuse entre líderes pentecostais entre 2008 e 2009, em Buenos Aires, Porto Alegre e Montevidéu. Descobrimos que, para além da presença das grandes denominações neopentecostais brasileiras nos países platinos, há outro movimento que permanece desconhecido. Líderes de renome no universo evangélico argentino, como o evangelista Carlos Annacondia e o pastor Claudio Freidzon, estenderam sua reputação e influência para dentro do campo pentecostal em Porto Alegre e Montevidéu, através de redes de relações mantidas desde a década de 1980. Já foi publicado material sobre essas relações noutra oportunidade (Alves, 2009), sendo que aqui exponho a opção teórico-metodológica que orientou a coleta de dados.

\section{A carne ou os ossos: origem e derivações do conceito de rede na tradição antropológica}

É amplamente conhecido que a antropologia inglesa no século XX forneceu à disciplina dois grandes patriarcas. Um deles, Bronislaw Malinowski, foi o que desenvolveu o método que distinguiria a antropologia das outras disciplinas; Alfred Radcliffe-Brown, a teoria que permitiria a institucionalização da disciplina como campo acadêmico e de pesquisa. O produto dessa junção foi um estilo descritivo que era ao mesmo tempo empiricista e formalista. Os estudantes eram estimulados a descrever o campo até a exaustão, e, conjuntamente a isso, a produzir teorias unificadoras dos dados que pudessem valer não apenas para o estudo específico. Os dois antropólogos deixaram, por assim dizer, uma legião de descendentes, que ora reivindicavam herança junto a um ou rechaçavam os seguidores do outro.

Um dos levantes anti-Radcliffe-Brown tinha como mote o estudo de redes sociais e foi gestado dentro do seminário de Manchester na década de 1950, conduzido por Max Gluckman. Foi dentro desse ambiente acadêmico que surgiu o primeiro trabalho sobre redes sociais em antropologia, de J. Barnes, sobre processos políticos numa comunidade religiosa na Noruega em 1954 (segundo Mitchell, 1974). Três anos depois desse artigo de Barnes, 
Elizabeth Bott (1976) lançou Família e rede social, livro de referência no tema, com dados coletados nos distritos suburbanos de Londres numa pesquisa que envolvia pesquisadores de muitas áreas das ciências humanas. Sua hipótese central era de que a diferenciação de papéis sexuais no casal era tão intensa quanto fossem os contatos do núcleo com a família extensa e com a vizinhança. Tratava-se de um contraponto em relação ao estrutural-funcionalismo de Radcliffe-Brown, e a outro tipo de estruturalismo de cunho sociológico que vinha sendo desenvolvido por Talcott Parsons nos Estados Unidos. A diferenciação sexual tradicionalmente era vista como instituição social, regulada por normas que se distribuíam de maneira homogênea e sancionavam negativamente os disfuncionais. Na proposta de Bott, padrões de comportamento institucionalizados eram colocados como fatores dependentes em face da situação do núcleo familiar dentro de uma rede de relações que lhe era externa.

O desenvolvimento desse tipo de abordagem merece ser visto em seu contexto. A descolonização africana estava levando os antropólogos a descreverem situações sociais bastante complexas, não mais redutíveis aos modelos que isolavam os grupos nativos na redoma da inocência pré-moderna. Os trabalhos de Max Gluckman (2010), um dos estimuladores principais dos estudos de rede, expressam a preocupação de, na descrição das relações entre grupos, revelar dinâmicas complexas nessas sociedades que saíam do jugo colonial europeu.

No livro de Bott (1976), como no primeiro artigo sobre redes sociais de Barnes, partiu-se de uma ideia de rede, mas não de uma teoria. Geralmente esses estudos identificavam características que descrevem o fenômeno, mas procuravam-se as explicações sobre como as redes influenciavam as relações humanas a posteriori. Segundo o antropólogo americano Clyde Mitchell (1974, p. 280, grifo do autor, tradução minha),

De fato, os primeiros relatos de campo fazendo uso da noção de redes sociais, como os de Barnes, Bott e Philip Mayer, forneceram dados de campo insuficientes sobre a natureza intrínseca das redes sociais para permitir que as descobertas relatadas nos estudos fossem checadas. Esses estudos, representando os inícios do uso analítico das redes sociais, eram talvez apresentados dessa maneira porque os escritores alcançavam a utilidade da natureza da rede social depois que tinham coletado seus dados de campo, e porque nos tempos em que foram escritos a panóplia de conceitos e índices que estão disponíveis ao antropólogo hoje simplesmente não tinha sido desenvolvida.

Horizontes Antropológicos, Porto Alegre, ano 18, n. 37, p. 45-71, jan./jun. 2012 
Nesse mesmo artigo, Mitchell identifica a inexistência de "uma teoria das redes propriamente dita". Assinala duas abordagens diferentes no estudo de redes, e duas características desse tipo de organização social, que penso ainda serem válidas. A abordagem estrutural procura explicar o comportamento dos indivíduos pela sua condição em redes sociais, o que segundo o antropólogo de Oxford (Mitchell, 1974, p. 285, tradução minha) "é mais ou menos uma extensão da busca durkheimiana por solidariedade e consenso". Temos, aqui, um desenvolvimento no estudo de redes sociais que, em seus supostos básicos, aproxima-se do estrutural-funcionalismo. A ruptura que Barnes e Bott, por exemplo, fizeram com a tradição foi relativa, pois mantiveram a preocupação com elementos normativos de comportamento que as relações em rede mantinham.

Por outro lado, a abordagem transacional enfoca como indivíduos manipulam as redes de relações para obterem vantagens práticas para si. Termos correntes em antropologia como "agência” e "ator social”, em suas raízes, são fundamentados nessas concepções de intencionalidade e racionalidade. Ela já estava presente, por exemplo, nos livros de Erving Goffman (1982, 1990). O estigma, tido como "patologia social” na tradição antiga de interpretação socioantropológica, faz parte dos repertórios identitários através dos quais os indivíduos manipulariam as suas relações dentro de instituições totais. A metáfora do jogo, no qual os indivíduos representam-se cotidianamente assumindo identidades e administrando a tensão entre o rigor das normas com as suas próprias vontades, tornou-se um dos lugares-comuns do discurso antropológico contemporâneo (Geertz, 1997).

Mitchell também estabelece características que permitiriam descrever redes. Características morfológicas seriam analisáveis a partir da elaboração de gráficos de relações a partir de uma "âncora”, o sujeito que é ponto de partida da descrição da rede. A condição para um sujeito ser considerado "âncora" é, antes de tudo, sua posição como aglutinador de relações dentro de um processo. Ele se torna o primeiro nó de um gráfico, que depois será complementado pelo mapeamento de relações referidas pelo sujeito-âncora. Teríamos, então, sucessivas "estrelas” de relações enfeixadas, formalizadas em gráficos (por exemplo, em Barnes, 2010). Seria possível determinar, através de alguns cálculos matemáticos, que a densidade de relações em certos pontos da rede acaba direcionando, por exemplo, o rumo de decisões coletivas (por exemplo, em Mayer, 2010). O problema, desse ponto de vista, é como dar visibilidade

Horizontes Antropológicos, Porto Alegre, ano 18, n. 37, p. 45-71, jan./jun. 2012 
analítica a grupos que não estão em contato contínuo e formal, mas que atuam de forma "corporada”. Mas como precisar, na extensão de uma rede de relações que teoricamente pode ser ilimitada, quais características o levam a ser um conjunto-de-ação (action-set), quase-grupo (quasi-group) ou, ainda, determinar as relações entre essas subdivisões? São questões que dividem os aderentes ao método.

As características interacionais das redes dizem respeito a seus aspectos qualitativos (durabilidade, intensidade e frequência dos contatos, por exemplo). Essas características qualitativas distinguem o “quase-grupo” para Adrian Mayer (2010), cujo conceito é sintetizado por Mitchell (1974, p. 294) dessa forma: um conjunto de pessoas que atuam de forma corporada em muitas ocasiões e que, se continuarem a fazer o mesmo em ocasiões futuras, mantendo um arranjo interno de atividades ou uma estrutura de relacionamentos, talvez se torne um grupo corporado.

A identificação e análise de subgrupos dentro de redes amplas podem, também, ser alvo de estudos quantitativos. Isso nos leva ao terreno dos aspectos morfológicos das redes, estudados principalmente por sociólogos e psicólogos. Para se ter ideia do refinamento técnico a que se chegou nesse terreno, basta folhear certas edições de Social Networks, uma revista que publica desde o fim dos anos 1970 artigos que têm uma abordagem quantitativa de network studies, que envolve programação de computadores e cálculos avançados (ver, por exemplo, Frank, 1995, 1996 e Doreian e Mrvar, 1996). Isso levou à replicação da dicotomia entre métodos qualitativos e quantitativos, geral nas humanidades, para dentro do estudo de redes. A compreensão de boa parte desses textos só é possível para pessoas familiarizadas com matemática e programação, o que distancia os antropólogos de uma avaliação positiva desse tipo de "estrutura sem carne".

Clyde Mitchell (2010) afirma que essa clivagem metodológica é artificial, contudo privilegia a abordagem qualitativa, admitindo a quantificação na pesquisa em redes sociais como suporte para o trabalho de campo. Jeremy Boissevain (1979, p. 392, tradução minha), antropólogo social, descreve de seu ponto de vista que:

A análise de rede disponibilizou um enquadramento analítico para dados num nível mais baixo de abstração do que o complexo institucional. É mais "rés do chão". Além disso, disponibilizou também dados aparentemente "duros” [hard]

Horizontes Antropológicos, Porto Alegre, ano 18, n. 37, p. 45-71, jan./jun. 2012 
que podem ser diagramados e mesmo computadorizados. Esse último recurso foi particularmente invocado por sociólogos, que, mais do que antropólogos, parecem revelar dados que podem ser quantificados e encaixados em elaboradas fórmulas, desse modo parecendo dar suporte a sua reivindicação de serem considerados [sic] uma hard science.

Há textos que tentam unir as duas tradições que se erigiram (por exemplo, em García-Álvares e Lopes-Sintas, 2002), mas normalmente se faz uma escolha entre "a carne ou os ossos", para usar uma metáfora conhecida (Malinowski, 1978). Para dar exemplo recente, logo ao início de um livro recém-lançado sobre redes transnacionais na América Central, os organizadores antecipam que não se trata de uma análise estrutural de redes (social network analysis, SNA), mas sim de estabelecer: 1) suas origens e objetivos; 2) a forma que reconfiguram o espaço e a geografia da região; 3) as mudanças que produzem nas relações entre autoridades estatais e habitantes, e nas relações entre as sociedades da região (Saltalamacchia; Tickner, 2007, p. 9).

Em meu trabalho, encontro alguns elementos que estimulam a uma analise qualitativa de redes. Primeiro, observa-se a importância de certas relações que funcionam como canalizadores dentro do terreno pentecostal e carismático, abrindo o terreno para que outras pessoas com os mesmos interesses que vivem em países diferentes se encontrem e estabeleçam também contatos. Isso vai gerando uma sensação de "grupo corporado”, ou seja, de uma espécie de “comunidade” com certos princípios e normas, e no qual há produção, distribuição e consumo de capital de reconhecimento pessoal. Indissociável a isso é o fato de que essas aproximações visam um benefício pessoal, seja em termos de prestígio dentro do campo religioso local ou do crescimento numérico do grupo a que se pertence. Há alguns exemplos de pastores argentinos que têm relações de amizade muito estreitas com brasileiros, e que dinamizaram os encontros entre as respectivas redes de pastores nas regiões onde atuam por conta dessa relação.

A abordagem antropológica mais tradicional, na medida em que se dedica à análise das maneiras, dos objetos e das crenças concernentes aos sistemas de troca, contribui para o estudo de redes transnacionais de agentes religiosos. E também de seu sentido: para onde os fluxos estão se dirigindo? Como tese geral, defendo que, no meio pentecostal, entre Brasil e Argentina, desde a década de 1980 tem acontecido uma via de mão dupla. Por um lado, 
as grandes igrejas brasileiras buscam espaço nos grandes centros urbanos argentinos, e, por outro, agentes religiosos argentinos têm aumentado seu espectro de influência diante de pequenos e médios empreendimentos religiosos em Porto Alegre.

\section{Sociedades em rede, globalização e fluxos}

Na década de 1990, os estudos de redes passaram a contar com uma nova gama de significados associados à globalização, sociedade da informação e cibercultura. Com o fim da União Soviética e o arrefecimento do marxismo nos meios universitários, passou-se a entender que o capitalismo intensificou a criação de redes de produção, circulação e consumo que extrapolavam a lógica das divisões territoriais nacionais. Logo, a unidade entre território e soberania nacional estava a perigo por conta das pressões do mercado; na visão crítica do geógrafo Rogério Haesbaert (2004, p. 26), “as ciências sociais redescobrem o território para falar de seu desaparecimento”.

A trilogia de Manuel Castells foi uma das obras que mais divulgou essa reentrada do conceito de rede na teoria social, tomando globalização como objeto. $\mathrm{O}$ argumento central exposto no início da obra de Castells seria de que o capitalismo está cada vez mais articulado em redes mundiais de circulação de capitais e produtos, e que isso tem um impacto na maneira através da qual as pessoas se identificam. As redes, para Castells, são globais; as identidades, embora possam ser estimuladas pelo processo de globalização, são locais (Castells, 2000a, argumento comum a Harvey, 1992). Os conceitos de identidade de resistência e identidade de projeto estão sempre ligados ao reforço de uma dimensão cultural particular (Castells, 2000a, p. 24). Como bem afirmado pela antropóloga Ruth Cardoso, na introdução do segundo volume, "é um desenvolvimento importante da teoria da mudança social”, e, por isso mesmo, traz enquadramento iluminista e "integrado" da globalização (poder-se-ia dizer "otimista”, embora Castells apresente-se mais propositivo que otimista).

Há várias possibilidades de construir significado com o conceito "globalização”, e aqui serão descritas apenas duas para fim de análise. A primeira é mais geral, e descreve a globalização como um processo de larga escala. Assume-se que a aceleração de nossa noção de tempo encurtou a de espaço (Robertson, 1996), e que isso alterou consideravelmente a maneira através 
da qual percebemos o mundo como totalidade. A expansão da rede mundial de computadores produziu uma realidade nova, na qual a informação circula em escalas antes apenas imaginadas. A globalização financeira fez com que o capital se volatilizasse de tal forma que, no mercado internacional, as apostas dos investidores mudam em instantes. No plano demográfico e político, intensificou-se o fluxo mundial de imigrantes no sentido sul-norte, o que aumentou os problemas de sustentação do welfare state nos países europeus. Aqui já entramos na segunda abordagem possível: a da globalização enquanto objeto de estudo. Aqui, assume-se como fato tudo o que é válido para a globalização como processo, sendo que: 1) vigora um materialismo de fundo que restringe o estudo aos fluxos migratórios, financeiros e políticos, levando os aspectos culturais (como a informação e a religião) como variáveis dependentes das primeiras; 2) a sociedade nacional continua a ser a unidade de análise.

A globalização como objeto, como veremos, não é o único descritor teórico utilizado para descrever o processo de globalização. Os cientistas sociais passaram a investigar, sob a égide de outros descritores associados a esse processo, como internacionalização, diáspora e transnacionalização, os fluxos de informação, bens materiais e simbólicos, e as conexões entre mundos culturais em escala global. Os artigos publicados nessa linha analisam desde correntes migratórias contemporâneas até organizações empresariais ou não governamentais de grande escala, passando por organizações profissionais, religiosas, etc. Há uma diversidade de objetos de estudo que não necessariamente passam pelo deslocamento físico de pessoas:

No período contemporâneo, os limites nacionais são constantemente entrecruzados por processos de comunicação e troca que não incluem mobilidade [bodily movement], como a expansão do capital, internet e outras telecomunicações. Outros modos de mobilidade transnacional, tais como turismo [...] não englobam migração. Todas essas relações são mediadas por compreensões translocais. (Smith; Guarnizo, 1998, p. 14, tradução minha).

As abordagens que teóricos da globalização e atores sociais com ação voltada em nível global podem projetar foram mapeados por Pries (2005, p. 172) em configurações ideais-típicas. Modifiquei o esquema deste autor, diferenciando globalização como processo (mais geral) e como objeto (como uma das possibilidades de abordagem), ainda adicionando um par de 
categorias referentes à constituição identitária frente ao processo de integração global, “centralidade” e “dispersividade”. Exponho primeiramente o gráfico, analisando-o na sequência.

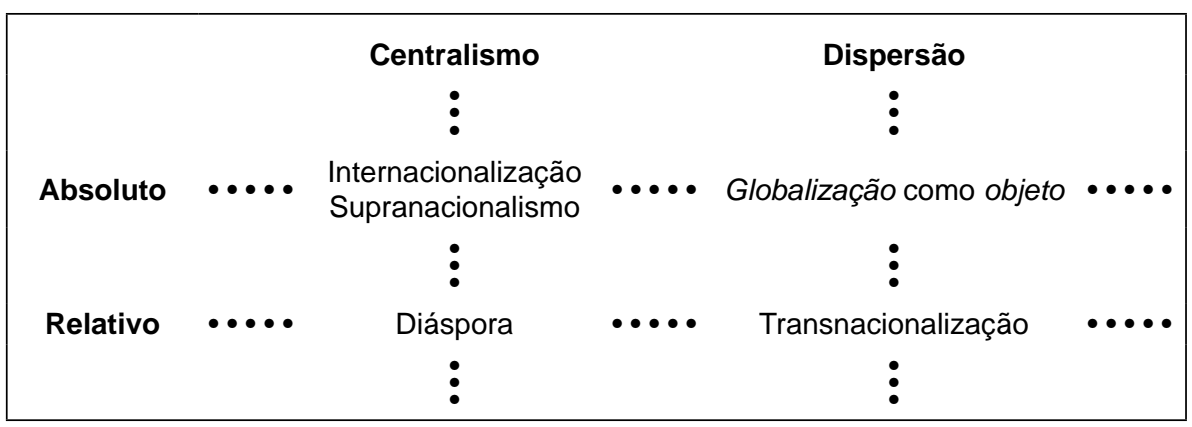

Gráfico 1. Esquema de tipos-ideais associados à globalizacão enquanto processo (elaborado a partir do levantamento bibliográfico de Pries, 2005, p. 176).

As linhas referem-se à correspondência entre espaço social e espaço geográfico. Quando absoluta, afirma-se que existe uma correspondência precisa entre uma sociedade e um território, no sentido clássico da geografia política. Na segunda linha, admite-se que os espaços sociais podem ser constituídos por muitos espaços geográficos, ou que um mesmo espaço geográfico pode ser constituído por vários espaços sociais. As colunas assinalam à constituição de identidade: quando a ênfase cai no centralismo, atenta-se para a existência formas de comunitarização que recriam, por rituais ou formas de sociabilidade, uma "nação" ou uma comunidade de nações. Se optarmos por “dispersão", a ênfase recairá nas formas através das quais as identidades locais alteram-se frente ao avanço da interdependência (econômica, social, cultural) em níveis globais.

Temos então:

1) Internacionalização - correspondência absoluta entre espaço geográfico e social, através da concepção de território típica da geografia política e das relações internacionais. Uma derivação desse tipo seria o "supranacionalismo", que orienta as federações de organizações que reúnem setores econômicos ou profissionais, ou mesmo Estados-Nação (como a União Europeia). 
2) Globalização como objeto - processo de intensificação de relações sociais percebidas como sendo de alcance mundial. Porém o espaço geográfico é sempre referido como sendo contíguo e coerente, não importa o quão (des)territorialista seja a teoria (Pries, 2005, p. 178). Autores como os já mencionados Harvey e Castells, ou ainda Berger e Huttington (2004), dependem desse "nacionalismo metodológico".

3) Diáspora - reconstituição de lugares dispersos como sendo partes de um "centro", como nos casos das representações diplomáticas ou das identidades étnico-religiosas judaicas ou palestinas.

4) Transnacionalização - processos que envolvem relações sociais espalhadas e multilocais, que atravessam fronteiras nacionais sem referência necessária a um centro, associadas ou não a processos migratórios.

Assim como a concepção de correspondência absoluta entre espaço geográfico e societal leva a um "nacionalismo metodológico", uma concepção relativista nos leva a ideia de "espaço de fluxos". Ela está descrita em Castells ${ }^{1}$ (2000b, p. 435-442), e a imagem geral que podemos ter a partir dela é a de sociedades coordenadas com base em impulsos eletrônicos, onde se perde a lógica dos lugares e as elites globais são completamente desenraizadas, embora tenham que manter seus sinais de distinção frente ao restante do povo, agora em escala global. Esse tipo de arranjo social influi na maneira com a qual produzimos espaço e arquitetura.

Nessa rede, nenhum espaço existe por si mesmo, já que as posições são definidas por fluxos. Consequentemente, a rede de comunicação é a configuração espacial fundamental: os lugares não desaparecem, mas sua lógica e seu significado são absorvidos na rede. (Castells, 2000b, p. 437).

Ulf Hannerz (1997, p. 15), inclusive, faz ressalvas ao uso demasiadamente relativista dos fluxos: “o que a metáfora do fluxo nos propõe é a tarefa de problematizar a cultura em termos processuais, não a permissão para desproblematizá-la, abstraindo suas complicações”. A intensificação dos fluxos

\footnotetext{
1 Ainda que, em larga medida, a trilogia de Castells deva muito ao “nacionalismo metodológico”, e por isso, o conceito de globalização nesse autor mantenha ainda uma relação absoluta entre espaço geográfico e societal.
} 
leva necessariamente à relativização das fronteiras? A resposta a essa pergunta envolve posições político-teóricas, e vários autores têm se posicionado contra a "tábula rasa" globalizante que homogeneíza na teoria o espaço e, por consequência, o tempo e o conflito. Talvez a linha de defesa mais consistente nessa recusa venha da geografia. E ela é antiga: a contraposição de Claude Raffestin (1993), na década de 1980, à geografia política clássica representou a adoção de uma concepção mais relativista de espaço, mas isso não implicou considerar os fluxos como o fim dos lugares. Ao adotar modelos de fluxos e redes, a consequência foi um esquadrinhamento da topologia desses fluxos, teoricamente embasada na tradição crítica francesa aos dispositivos de poder, principalmente em Henri Lefebvre e Michel Foucault. Atualmente, podemos mencionar a obra do geógrafo Milton Santos como uma contribuição fundamental nessa linha, e a Haesbaert (2004) pela produção, a partir da geografia, de crítica aos usos mais relativistas da noção de espaço endossadas por cientistas sociais.

Os desenvolvimentos dessa linha de pesquisa fazem com que as questões relativas à globalização, à desterritorialização e o fim das fronteiras sejam submetidas a exames críticos interessantes, que nos aproximam de uma análise de processos transnacionais recuperando a teoria crítica como base sem admitir o fim dos lugares e das memórias coletivas. Segato (2007) torna evidente tal posição quando considera os processos de expansão das religiões pentecostais e afro-brasileiras dentro de formações nacionais de alteridade que envolvem imbricações entre mitologias da nacionalidade e dispositivos de poder.

Na literatura sobre a relação entre globalização e culturas locais, com a qual o remanejamento da noção de rede dialoga, há duas tendências extremas que poderíamos identificar como ideal-típicas. Na primeira, assume-se que a expansão do american way of life põe em risco as formas de vida que destoam dele, solapando identidades nacionais e étnicas definidas, conduzindo as sociedades aos princípios de mercado, etc. ${ }^{2}$ Por outro lado, pode-se tomar a ação de certos grupos transnacionais de forma tão "desterritorializada” e repleta de agência que se perde de vista que essas relações sociais devem muito a fatores nacionais e locais. Há então o risco, nessas análises mais prêt-à-porter

\footnotetext{
2 Explicar o ressurgimento ou invenção de identidades locais tornou-se um dos temas mais importantes na discussão sobre globalização. Ver, por exemplo, Castells (2000b), Sahlins (1997a, 1997b), Kuper (2002) e, para a análise do caso do tradicionalismo gaúcho, ver Oliven (1992).
} 
da globalização, de obscurecer o fato de que o conteúdo e a direcionalidade dos fluxos (sejam eles de pessoas, de bens ou fluxos culturais) traduzem múltiplas assimetrias de poder em escala global. Embora essa seja uma ressalva muito comum nos textos sobre esse tema, Segato (2007) tem assumido essa condição como base paradigmática da reflexão teórica, e não somente como uma ressalva.

$\mathrm{Na}$ antropologia, desde a recusa do difusionismo, tanto pelo funcionalismo inglês (Radcliffe-Brown, 1973) quanto pelo culturalismo americano (Boas, 1940), sabemos que não se pode analisar o sentido de um item cultural que se desloca sem buscar sua significação no novo contexto. Por isso, na análise desses deslocamentos e dessas redes de relações com as quais no momento estamos em contato, deve se considerar tanto as formações de alteridade quanto a formação dos campos religiosos nacionais. Aqui me aproprio da noção de campo religioso de Bourdieu (1987), como um espaço social constituído com e a partir de um campo semântico, no qual existe uma economia simbólica de produção, distribuição e consumo de bens religiosos, e consequentemente relações de poder e dominação. As redes de relações não se limitam aos campos, mas se espalham por dentro ou por fora deles, e isso tem implicações para a aceitação local desse agente religioso como legítimo ou ilegítimo no âmbito local.

Atualmente, percebe-se que as igrejas brasileiras como a IURD e Deus é Amor se instalaram nas grandes cidades argentinas, mas elas não têm necessariamente o respaldo dos líderes pentecostais locais. A visão missionária agressiva dessas igrejas brasileiras faz com que sejam descritas como algo à parte pelos pastores argentinos, tanto é que um ex-presidente de uma das maiores associações evangélicas da Argentina fez-me uma ressalva no meio de uma entrevista: "quando falamos de evangélicos, não estou me referindo à Universal, não temos relação com eles”. Por outro lado, os principais pastores e evangelistas argentinos possuem contatos com pastores brasileiros, ou seja, eles os tecem por dentro do campo evangélico, entre denominações de pequeno e médio porte (de menos de 20.000 membros). Não fundam novas igrejas no Brasil, mas podem fazer aconselhamento pastoral (mesmo à distância, via Internet) ou mesmo viajar para o Brasil a convite, através de relações que envolvem níveis diversos de reciprocidade, dependendo do caso. Vemos, portanto, que há dois deslocamentos diferentes: o das igrejas brasileiras que se internacionalizam, mesclando o modelo clássico de missões evangélicas 
com uma perspectiva empresarial corporativa; e o dos líderes de pequenos e médios empreendimentos que se transnacionalizam através de redes pessoais de influência.

\section{A contribuição da antropologia simétrica}

Outra maneira de estudar redes, combinando o empiricismo da tradição antropológica com análise linguística, está sendo proposta por Bruno Latour ao longo dos últimos anos. Os usos do conceito de rede em Latour estão intrinsecamente ligados ao que ele denomina "antropologia da modernidade”. Esse projeto de antropologia está descrito em Jamais fomos modernos (Latour, 1994), numa sequência a etnografias em ambientes de produção científica (Latour, 1997, 2000). O conceito de rede em Latour deve, segundo Moraes (2000) e Freire (2006), a duas ideias concebidas por David Bloor e uma outra, pelo filósofo Michel Serres. Uma ideia cara a Latour, de Bloor, é a de que na história das ciências há uma tendência a estudar verdades e erros científicos em patamares diferentes. Ambos deveriam ser vistos como produções relacionadas ao contexto social que lhe cerca; contudo, na epistemologia mais tradicional, apenas as hipóteses descartadas são vistas como influenciadas pela sociedade, enquanto que a verdade parece ser sempre conquistada pela força inquestionável das evidências.

A ruptura com esse tipo de teleologia fez com que Latour estendesse esse tipo de raciocínio à maneira segundo a qual concebemos natureza e cultura. A cisão moderna entre natureza e cultura, que Latour (1994) identifica emblematicamente através do conflito entre o Leviatã de Hobbes e a bomba de vácuo de Boyle, levou a uma clivagem entre natureza e cultura aprofundada pela divisão do trabalho científico. Com o tempo, as Naturwissenchaften nada teriam a dizer sobre as relações de poder (elas nos ultrapassam), mas afirmariam a possibilidade da imanência em relação à natureza, pela constituição do espaço de laboratório. Assim como as Geisteswissenchaften diriam que os homens criam a vida social, ao mesmo passo que remeteriam tudo que fosse "natural” a uma dimensão transcendente. Essa rede de paradoxos entre natureza e sociedade, imanência e transcendência, compõem o que Latour (1994, p. 37) denomina a "terceira garantia” da constituição moderna: "o trabalho de purificação deve sempre permanecer distinto do trabalho de mediação”.

Horizontes Antropológicos, Porto Alegre, ano 18, n. 37, p. 45-71, jan./jun. 2012 
O pensamento moderno constitui seus objetos no centro do contínuo naturezacultura (mediação), para logo depois purificá-los novamente, levando-os aos extremos desse contínuo.

Acreditar nessa incomensurabilidade entre natureza e cultura, afirma Latour, é ser moderno, e mesmo os pós-modernos não escapam dessa condição ao dissolver os fatos humanos à potência da crítica moderna, obliterando definitivamente o estudo dos híbridos natureza-cultura e, consequentemente, das redes. Atualmente, o processo de purificação dos fatos passou a não dar mais conta da complexidade de fenômenos que são tanto naturais quanto sociais (o que Latour denomina de híbridos), que proliferam no centro. A crise explicativa teria aumentado na segunda metade do século XX, e o índice mais claro de sua profundidade nas ciências humanas seria o sucesso do pósmodernismo, que para Latour apresenta sinais claros de demissão intelectual. Seria necessária a constituição de uma antropologia na qual natureza e cultura fossem vistas, ambas, como produzidas coletivamente. Isso seria o cerne de uma antropologia simétrica, ideia que Latour extrai do "programa forte" de estudos da ciência de David Bloor (1991), exposto no livro Knowledge and social imagery. Essa nova constituição, portanto, seria necessária para dar conta dos híbridos, criados e multiplicados pela grande divisão. Aqui há uma adaptação da "filosofia mestiça" de Michel Serres.

Portanto, Latour se dispõe a compreender como esses híbridos surgem nas comunidades de cientistas, a partir de mediadores humanos e não humanos. A ciência, assim pensada, nunca é completamente autônoma. Cientistas sempre estão às voltas com fatores que lhe são externos e internos ao campo; e dentro do campo, influenciam-nos fatores externos e internos à ordem de discurso científico. Contudo, sua produção discursiva, pelo efeito do trabalho em rede, não pode ser descrita como um processo linear, ao gosto de uma epistemologia que só celebra as vitórias da ciência.

Sendo assim, como fazer um estudo de redes via a teoria de Latour? Em Jamais fomos modernos, o antropólogo francês faz algumas observações gerais sobre as redes. Recusa-se, por exemplo (Latour, 1994, p. 115), a confundir o global com o universal, num contraponto claro aos estudos sobre globalização mencionados acima. Uma rede ampla, para Latour, é local em todos os seus pontos, mas é global também, porque transporta pessoas, cargas, informações de um ponto a outro. E nem por isso os enunciados que as redes transportam e transformam devem ser confundidos com universais, porque

Horizontes Antropológicos, Porto Alegre, ano 18, n. 37, p. 45-71, jan./jun. 2012 
conectam pontos de forma assistemática. Chega a considerar que os conceitos de local e global não se aplicam ao estudo de redes (Latour, 1994, p. 116-117), fato que o distancia dos teóricos da globalização e da "sociedade em rede" há pouco mencionados:

Local e global, entretanto, são conceitos bem adaptados às superfícies e à geometria, mas inadequados às redes e à topologia. [...] O percurso das ideias, do saber ou dos fatos teria sido facilmente compreendido caso os houvéssemos tratado como redes técnicas. [...] O percurso dos fatos torna-se tão facilmente traçável como o das ferrovias ou dos telefones, graças a essa materialização do espírito que as máquinas de pensar e os computadores permitem.

Seguindo essa sugestão, podemos tomar uma ideia surgida em determinado ponto de uma rede (uma nova teoria ou técnica, ou mesmo uma nova prática ritual, se pensarmos em religião), tomá-la como um híbrido e ver como sucessivas alterações vão se criando sobre ela em rede, aumentando a aceitação ou rejeição da nova proposta (modalizando-a) ao mesmo tempo em que a transformam (modificando-a).

Num artigo sobre gráficos sociotécnicos, Latour, Mauguin e Teil (1992) sugerem que a construção de um fato em meio científico deve, antes de tudo, não replicar a divisão natureza-cultura para dentro dos dados. Em termos gerais, é possível caracterizar a proposta metodológica deste artigo como uma combinação de análise de conteúdo estruturalista com certos elementos que lembram as análises morfológicas dos estudos de rede aos quais se fez referência anteriormente.

A parte estruturalista do método diz respeito ao desmembramento dos enunciados de mediadores ${ }^{3}$ em séries sintagmáticas (de modalização) e ordens paradigmáticas (de modificação) dispostas em cartões, bem ao estilo de estudo dos mitos de Lévi-Strauss (1996). Contudo, não importa uma ordem das ordens aqui. A essência de um fato é a trajetória que liga as metamorfoses

\footnotetext{
Sobre o conceito de mediação em Latour (1994, p. 80): "Essas metamorfoses [através das quais as noções de natureza e cultura se transformam, como o que ocorreu depois bomba de vácuo de Boyle] tornam-se explicáveis se distribuirmos sua essência por todos os seres que compõem essa história. Mas então eles deixam de ser intermediários mais ou menos fiéis. Tornam-se mediadores, ou seja, atores dotados da capacidade de traduzir aquilo que eles transportam, de redefini-lo, desdobrá-lo, e também de traí-lo.”
}

Horizontes Antropológicos, Porto Alegre, ano 18, n. 37, p. 45-71, jan./jun. 2012 
(Latour, 1994, p. 85). O princípio de conectividade das redes, aplicado a organizações rizomáticas, postula que se devem considerar todos os seres em interação na rede ${ }^{4}$. Cada versão do fato, construída por coletivos de humanos e artefatos não humanos, vai compondo o que Latour descreve como "ontologias de geometria variável”.

Latour operacionaliza esse mapeamento das metamorfoses em gráficos. Uma série de índices matemáticos é montada para dar conta do processo de “estabilização” do fato científico por meio da circulação em rede. Dividindo um primeiro enunciado em pequenos elementos, temos um actante (uma constatação nova a respeito de alguma reação química, por exemplo) que vai sendo agregado a outros no processo de discussão científica. Seria possível calcular, por exemplo, um "índice de negociação" (Latour; Mauguin; Teil, 1992, p. 12-13) em cada uma dessas agregações, que seria o quociente do número de elementos novos agregados ao processo e do número de elementos associados na versão. Esse índice seria importante para perceber o grau de estabilização do fato, ou seja, a sua disposição no continuum que vai da existência à essência (ver gráfico em Latour, 1994, p. 85).

Os lugares onde essas metamorfoses (ou, em outro termo bastante utilizado por Latour, transformações) que geram os fatos científicos são os interstícios das redes. Nessas regiões, como nos rizomas, "tudo não cessa de ser composto":

Um rizoma não cessaria de conectar cadeias semióticas, organizações de poder e ocorrências relativas às artes, às ciências, às lutas sociais. Uma cadeia semiótica é como um tubérculo aglomerando atos muito diversos, não somente lingüísticos, mas também perceptivos, miméticos, gesturais e cogitativos: não existe língua em si, nem universalidade da linguagem, mas um concurso de dialetos, patuás, de gírias, de línguas especiais. (Deleuze; Guattari, 1995, p. 15-16).

$\mathrm{O}$ aspecto de heterogeneidade dos rizomas pode ser percebido na caracterização de Latour e Hermant (1996, p. 34, tradução minha) das redes,

4 Recordamos a posição de Deleuze e Guattari (1995, p. 15, grifo dos autores) sobre organizações rizomáticas, que influenciou a perspectiva de Latour: “Os agenciamentos coletivos de enunciação funcionam, com efeito, diretamente nos agenciamentos maquínicos, e não se pode estabelecer um corte radical entre regimes de signos e seus objetos.” 
quando descrevem o campo científico sem perder a dimensão da dominação que lhe é intrínseca:

O controle intelectual, a dominação douta, não se exerce diretamente sobre os fenômenos - galáxias, vírus, economia, paisagens - mas sobre as inscrições ${ }^{5}$ que lhe servem de veículo à condição de circular em contínuo nos dois sentidos através de redes de transformações - laboratórios, instrumentos, expedições, coleções.

Recuperando as terminologias de Clyde Mitchell, diria que o método que Latour, Mauguin e Teil propõem no artigo de 1992 é centrado na circulação de informação de uma parte a outra, e inclui o estudo de alguns seus aspectos morfológicos. Contudo, essa circulação não poderia ser descrita como pontos que se ligam num plano. Os cálculos desenvolvidos para esse tipo de estudo são utilizados para descrever as transformações dos enunciados, e não a geometria euclidiana dos atores, como, por exemplo, encontramos nos textos de análise morfológica das redes. As redes em Latour se aproximam mais do modelo rizomático de Deleuze e Guattari (1995), nos seus aspectos de conectividade, heterogeneidade e multiplicidade. Por fim, para uma antropologia simétrica, as variações que uma determinada informação sofre no decorrer do processo importam mais do que saber qual a fidedignidade em relação ao seu início (o que nos levaria a um reestabelecimento do difusionismo em termos mais sofisticados).

Logo, a compreensão do que é uma "rede” para Bruno Latour distancia-se substancialmente daquela mais tradicional na antropologia. Em termos de pesquisa, não poderíamos mais contar só com mediadores humanos, as "relações pessoa a pessoa” do estrutural-funcionalismo antropológico. Resgataríamos, numa perspectiva simétrica, a historicidade dos enunciados dentro de uma aramagem complexa de mediadores humanos e não humanos, ambos considerados com agência real e transformando-se mutuamente. Para dar um exemplo do próprio Latour: o surgimento das bactérias enquanto enunciado científico construído no ambiente de um laboratório no século XIX faz surgir, dentro

\footnotetext{
5 Por “inscrição” Latour entende a informação que transita materializada em cartas, mapas genéticos, quadros, relatos de viajantes, etc. Considera também que a informação é uma relação estabelecida entre dois lugares que transita de uma periferia para um centro.
}

Horizontes Antropológicos, Porto Alegre, ano 18, n. 37, p. 45-71, jan./jun. 2012 
do que se imagina como "natureza", um novo agente, e na "sociedade", um novo Louis Pasteur, agora com a carreira científica consagrada pela descoberta dos micróbios e pelas sucessivas discussões científicas geradas a partir dela (Latour, 2001).

Qual a contribuição do repertório teórico-metodológico de Latour num trabalho que envolvesse pastores e missionários e evangélicos que se conhecem e circulam entre fronteiras nacionais a partir desses contatos? Uma sugestão possível seria a de atentar tanto à circulação de pessoas quanto à de informações, e às transformações que acontecem nas práticas religiosas em deslocamento.

Nessas idas e vindas, os agentes religiosos em questão aprendem uns com os outros, interagindo com novas formas de abordagem, de conduzir o culto e mesmo performances rituais que desconhecem. Sabe-se que há algumas inovações rituais desenvolvidas no campo do pentecostalismo, como, por exemplo, o descanso no espírito, no qual o pastor impõe a mão sobre o fiel e ele cai no chão, numa espécie de sono profundo. A difusão dessa prática verifica-se em grupos carismáticos católicos, que podem associá-la com processos de cura envolvendo o afastamento de demônios geracionais Steil (2006). A possessão de entidades de cultos afro-americanos, interpretadas como demoníacas em cultos pentecostais, já é bastante conhecida.

Quando instados a descrever tais práticas, os cientistas hesitam em darlhes crédito enquanto fenômeno, descrevendo-as em algum ponto do continuum ideal-típico (cultura/sociedade)-natureza. Ora fixam-se nos estados mentais individuais gerados por esses eventos, ora os associam com necessidades coletivas de eficácia mágica (e aqui Marcel Mauss e Max Weber são referências de base), ou mesmo partem para uma solução interpretativa centrada na experiência dos atores. Uma forma de reintegrar a experiência religiosa ao domínio do real seria a proposta de "ontologia de geometria variável”, como descrita por Latour, aplicada às práticas rituais religiosas. A trajetória das transformações de uma narrativa ritual, quando em deslocamento, seria a sua essência, e não a presumida eficácia de seu simbolismo.

Com a ênfase na transformação dos enunciados, o papel das mídias no pentecostalismo precisaria ser reconsiderado. Os estudos especializados na área da religião tendem a uma visão funcional e instrumental dos usos da mídia, o que ocorre por conta da centralidade do objeto científico "instituição religiosa” na análise desse segmento religioso. A equivalência entre "mídia” 
e "proselitismo" obscurece o papel dos mediadores não humanos enquanto transformadores do próprio pentecostalismo, até mesmo porque boa parte dessa mídia está voltada para a comunicação de uma experiência religiosa, da qual se espera, como consequência, que reverta para a adesão a uma instituição. A engenharia imagética e massiva da transformação subjetiva proporcionada por livros, por materiais informativos, por fitas cassete e de vídeo doméstico, por CDs e DVDs que circulam entre os pastores e os fiéis e pela internet não necessariamente subordina o sujeito a uma instituição, mas antes parece potencializar, nos últimos anos, o surgimento de mais grupos, todos baseados em mandatos divinos de líderes carismáticos e no uso dos meios digitais físicos e virtuais de comunicação. Aliás, a virtualidade midiática da experiência religiosa sempre fez parte do pentecostalismo. Pouco mais de cem anos atrás, distribuía-se um boletim chamado Apostolic Faith para 50.000 assinantes ao redor do mundo, anunciando os fenômenos sobrenaturais que estariam acontecendo na primeira igreja pentecostal moderna, na Azuza Street, em Los Angeles (Synan, 2005, p. 15). Hoje há pastores que promovem cultos via rede mundial de computadores: certa vez um deles proclamou, num culto transmitido pela web, enquanto orava por enfermos distantes: "os anjos do Senhor são mais rápidos que a internet”.

Finalizando essa parte, diria que algumas das consequências do aporte teórico de Latour para o estudo das religiões aproximar-se-iam da acepção de Sanchis (1994) do sincretismo como estrutura. Uma leitura puramente funcional do sincretismo relacionaria as adaptações das religiões aos contextos sociais de destino. Uma leitura do sincretismo inspirada em Latour estaria atenta não apenas às reestruturações simbólicas que permitem o diálogo com necessidades religiosas das populações-destino, mas também à transformação dessa prática religiosa ao longo do deslocamento, agenciada pela mediação tecnológica.

\section{Conclusões}

Portanto, ao falarmos em "redes”, temos pelo menos três possibilidades de entendimento, e cada uma delas nos leva a problemas de interpretação específicos. Na tradição antropológica, quando as redes eram compostas por relações pessoa a pessoa, alguns desafios se impuseram: a) como delimitar 
as redes e seus subconjuntos; b) o que considerar como fluxo; c) qual a metodologia a ser aplicada (qualitativa ou quantitativa); e d) como descrever processos a partir das relações mapeadas. Os primeiros trabalhos sobre rede na antropologia tinham caráter mais qualitativo e exploratório. Logo após, com a expansão do tema para outras áreas disciplinares, passou-se a responder primeiramente ao desafio “b”, para estabelecer categorias quantificáveis que permitissem delimitar os conjuntos-de-ação e as redes, respondendo ao ponto "a".

A antropologia simétrica tornou ainda mais complicados os dois primeiros desafios, na medida em que não humanos também são actantes. Num artigo de crítica à teoria do ator-rede de Latour, Strathern (1996) pontua claramente essa dificuldade de encontrar limites para a análise de redes, seja no estudo entre modernos ou não modernos, e sugere que há pontos em que as redes se rompem ou os fluxos cessam. Postula, ainda, que a divisão entre humanos e não humanos está sempre apoiada numa gama de outras divisões, que podem estar associadas, por exemplo, ao parentesco e ao comércio (Strathern, 1996, p. 519). O método proposto por Latour para delimitar processos, portanto, ainda está em discussão no meio acadêmico e ainda terá de ser avaliado com mais profundidade.

Foi examinado, ainda, outro direcionamento dos estudos de rede, mais associados às teorias da globalização. Aqui, admite-se que as sociedades da informação estão conectadas em rede. As redes, nesse caso, deixam de ser uma forma de descrição de relações para serem tomadas logo de saída como um estado a partir do qual relações sociais se processam no mundo contemporâneo, como uma nova física social, tomando livremente uma expressão de John Urry (2004). Gostaria de revisitar uma discussão que levantei na segunda parte do artigo, para delimitar o objeto a que me dediquei na tese (Alves, 2011) e a opção teórico-metodológica feita, dentre as três apresentadas aqui.

A partir da discussão sobre redes, e do Gráfico 1, elaborado a partir do artigo de Pries, afirmo que meu interesse recaiu sobre processos que ocorreram entre redes transnacionais. Opto aqui por transnacionalização e não por globalização. Embora o último termo forneça o quadro paradigmático no qual se insere a discussão que ora elaboro, quando menciono globalização enquanto processo, é forçoso admitir que nos últimos anos o conceito de globalização tornou-se foco de uma discussão que alargou demais suas implicações. Quando falo em transnacionalização, refiro-me a espaços sociais 
comuns construídos por redes, com níveis de institucionalização variáveis, atravessando espaços societários diferentes.

Esses espaços comuns compõem-se, no caso em que estudei, de pastores, evangelistas e músicos de três cidades em países diferentes (Porto Alegre, Montevidéu e Buenos Aires). Nenhum desses agentes era de uma mesma organização religiosa, contudo eles estabeleciam contatos e alianças entre si dentro processo micro-histórico de constituição de grupos pentecostais e carismáticos, desde as décadas de 1960 e 1970, nas três cidades (Alves, 2008). Dado que não encontrava na literatura especializada textos em que as conexões entre líderes viessem para o plano principal da análise, e que no meu caso elas eram numerosas, decidi-me por um estudo qualitativo de redes sociais, numa perspectiva clássica no referente ao uso empírico do conceito de rede, mas heterodoxa, no que diz respeito à dispersão do campo.

Não seria possível realizar etnografias clássicas em tantos lugares, em tão pouco tempo. Esse tipo de narratividade etnográfica, nas concepções mais antigas, "localiza" o nativo, fixando-o em um determinado ponto no mapa e delimitando, nesse território circunscrito, um modo de estar no mundo. O que as etnografias clássicas obliteram na análise, seguindo o raciocínio de James Clifford (1999), é que os nativos desde sempre viajaram, atravessando mundos culturais e incorporando na sua Weltanschuung as experiências desse atravessamento. Incorporar essa dimensão, nova apenas na análise, não leva à substituição do nativo pelo viajante. Isso o leva a questionar a localização dos sujeitos proporcionada pelas análises clássicas, e a fazer a seguinte pergunta: "De que modos as pessoas conformam redes, mundos complexos que por sua vez pressupõem e excedem as culturas e as nações?” (Clifford, 1999, p. 22, tradução minha).

Identifiquei o primeiro dos problemas levantados por Clifford com a problemática antropológica geral de meu trabalho, o que leva necessariamente a um tipo de etnografia mais extensiva, pois não há como tratar todos os nós principais da rede como etnografias completas, com todas as exigências canônicas de residência e interação contínua. De forma que optei (Alves, 2011) por uma etnografia multissituada ao longo de redes transnacionais constituídas entre agentes religiosos das três cidades mencionadas, mantendo no plano teórico um diálogo com as teorias da globalização e com certas consequências da antropologia simétrica.

Horizontes Antropológicos, Porto Alegre, ano 18, n. 37, p. 45-71, jan./jun. 2012 


\section{Referências}

ALVES, D. Conectados pelo Espírito: redes pessoais de contato e influência entre líderes evangélicos ao Sul da América Latina. Debates do NER, v. 10, n. 16, p. 183-199, 2009. Disponível em: <http://seer.ufrgs.br/debatesdoner/ article/view/12207/7214>. Acesso em: 15 jun. 2011.

ALVES, D. Conectados pelo Espírito: redes de contato e influência entre líderes carismáticos e pentecostais ao Sul da América Latina. Tese (Doutorado em Antropologia Social)-Instituto de Filosofia e Ciências Humanas, Universidade Federal do Rio Grande do Sul, Porto Alegre, 2011. Disponível em: <http://hdl.handle.net/10183/29406>. Acesso em: 15 jun. 2011.

BARNES, J. A. Redes sociais e processo político. In: FELDMAN-BIANCO, B. (Org.). Antropologia das sociedades contemporâneas. São Paulo: Global, 2010. p. 171-204.

BERGER, P. L.; HUTTINGTON, S. P. (Org.). Muitas globalizações: diversidade cultural no mundo contemporâneo. Rio de Janeiro: Record, 2004.

BLOOR, D. Knowledge and social imagery. Chicago: University of Chicago Press, 1991.

BOAS, F. The limitations of comparative method of anthropology. In: BOAS, F. Race, language and culture. New York: McMillan, 1940. p. 270-280.

BOISSEVAIN, J. Network analysis: a reappraisal. Current Anthropology, Chicago, v. 20, n. 2, p. 392-394, 1979.

BOTT, E. Família e rede social. Rio de Janeiro: Francisco Alves, 1976.

BOURDIEU, P. A economia das trocas simbólicas. São Paulo: Perspectiva, 1987.

CASTELLS, M. A era da informação: economia, sociedade e cultura: vol. 1: a sociedade em rede. São Paulo: Paz e Terra, 2000a.

CASTELLS, M. A era da informação: economia, sociedade e cultura: vol. 2: o poder da identidade. São Paulo: Paz e Terra, 2000b. 
CLIFFORD, J. Itinerarios transculturales. Barcelona: Gedisa, 1999.

DELEUZE, G.; GUATTARI, F. Mil platôs: capitalismo e esquizofrenia. Rio de Janeiro, Editora 34, 1995. v. 1. (Coleção Trans).

DOREIAN, P.; MRVAR, A. A partitioning approach to structural balance. Social Networks, n. 18, p. 149-168, 1996.

DURKHEIM, É. A divisão do trabalho social. Lisboa: Presença, 1984. v. 1.

DURKHEIM, É. As regras do método sociológico. Rio de Janeiro: Martins Fontes, 2002.

FRANK, K. A. Identifying cohesive subgroups. Social Networks, n. 17, p. 27-56, 1995.

FRANK, K. A. Mapping interactions within and between cohesive subgroups. Social Networks, n. 18, p. 93-119, 1996.

FREIRE, L. de L. Seguindo Bruno Latour: notas para uma antropologia simétrica. Comum, Rio de Janeiro, v. 11, n. 26, p. 46-65, 2006. Disponível em: <http://www.facha.edu.br/publicacoes/comum/comum26/artigo2.pdf>. Acesso em: 15 jun. 2011.

GARCÍA-ÁLVARES, E.; LOPES-SINTAS, J. Contingency table: a two-way bridge between qualitative and quantitative methods. Field Methods, v. 14, n. 3, p. 270-287, 2002.

GEERTZ, C. O saber local: ensaios de antropologia interpretativa. Petrópolis: Vozes, 1997.

GLUCKMAN, M. Análise de uma situação social na Zululândia moderna. In: FELDMAN-BIANCO, B. (Org.). Antropologia das sociedades contemporâneas. São Paulo: Global, 2010. p. 237-364.

GOFFMAN, E. Estigma: notas sobre a manipulação da identidade deteriorada. Rio de Janeiro: Zahar, 1982.

GOFFMAN, E. Manicômios, prisões e conventos. São Paulo: Perspectiva, 1990. 
HAESBAERT, R. O mito da desterritorialização. Rio de Janeiro: Bertrand Brasil, 2004.

HANNERZ, U. Fluxos, fronteiras, híbridos: palavras-chave da antropologia transnacional. Mana, Rio de Janeiro, v. 3, n. 1, p. 7-39, 1997.

HARVEY, D. Condição pós-moderna: uma pesquisa sobre as origens da mudança cultural. São Paulo: Loyola, 1992. (Coleção Temas de Atualidade, n. 2).

KUPER, A. O retorno do nativo. Horizontes Antropológicos, v. 8, p. 213-217, n. 17, 2002.

LATOUR, B. Jamais fomos modernos. Rio de Janeiro: Editora 34, 1994. (Coleção Trans).

LATOUR, B. A vida de laboratório. Rio de Janeiro: Relume-Dumará, 1997.

LATOUR, B. Ciência em ação: como seguir cientistas e engenheiros sociedade afora. São Paulo: Ed. da Unesp, 2000.

LATOUR, B. A historicidade das coisas: por onde andavam os micróbios antes de Pasteur? In: LATOUR, B. A esperança de Pandora. Bauru: Edusc, 2001. p. 169-200.

LATOUR, B.; HERMANT, E. Ces réseaux que la raison ignore - laboratoires, bibliothèques, collections. In: JACOB, C.; BARATIN, M. (Org.). Le pouvoir des bibliothèques: la mémoire des livres dans la culture occidentale. Paris: Albin Michel, 1996, p. 26-43. Disponível em: <http://www.bruno-latour.fr/ sites/default/files/64-JACOB-BIBAL-Published-FR.pdf > . Acesso em: 15 jun. 2011.

LATOUR, B.; MAUGUIN, Ph.; TEIL, G. A note on socio-technical graphs. Social Studies of Science, v. 22, p. 33-57, 1992. Disponível em: <http://www. bruno-latour.fr/sites/default/files/47-GRAPHS\%20SSofSpdf.pdf $>$. Acesso em: 15 jun. 2011.

LÉVI-STRAUSS, C. As estruturas elementares do parentesco. Vozes: Petrópolis, 1982. 
LÉVI-STRAUSS, C. A estrutura dos mitos. In: LÉVI-STRAUSS, C. Antropologia estrutural. Rio de Janeiro: Tempo Brasileiro, 1996. p. 237-265. (Biblioteca Tempo Universitárion, n. 7).

MALINOWSKI, B. Os argonautas do Pacífico Ocidental. São Paulo: Abril Cultural, 1978. (Coleção Os Pensadores).

MAYER, A. C. A importância dos quase-grupos no estudo das sociedades complexas. In: FELDMAN-BIANCO, B. (Org.). Antropologia das sociedades contemporâneas. São Paulo: Global, 2010. p. 139-170.

MITCHELL, C. Social networks. Annual Review of Anthropology, v. 3, p. 279-299, 1974. Disponível em: <http://links.jstor.org/sici?sici=00846570\%281974\%292\%3A3\%3C279\%3ASN\%3E2.0.CO\%3B2-Q>. Acesso em: 15 jun. 2011.

MITCHELL, C. A questão da quantificação na Antropologia Social. In: FELDMAN-BIANCO, B. (Org.). Antropologia das sociedades contemporâneas. São Paulo: Global, 2010. p. 89-137.

MORAES, M. O. O conceito de rede na filosofia mestiça. Revista Informare, v. 6, n. 1, p. 12-20, 2000.

OLIVEN, R. G. A parte e o todo. Petrópolis: Vozes, 1992.

PRIES, L. Configurations of geographic and societal spaces: a sociological proposal between 'methodological nationalism' and the 'spaces of flows'. Global Networks, v. 5, n. 2, p. 167-190, 2005.

RADCLIFFE-BROWN, A. R. Estrutura e função na sociedade primitiva. Petrópolis: Vozes, 1973.

RAFFESTIN, C. Por uma geografia do poder. São Paulo: Ática, 1993.

ROBERTSON, R. Globalização: teoria social e cultura global. Petrópolis: Vozes, 1996. (Coleção Horizontes da Globalização).

SAHLINS, M. O pessimismo sentimental e a experiência etnográfica: por que a cultura não é um objeto em via de extinção (parte I). Mana. Rio de Janeiro, v. 3, n. 1, p. 41-73, 1997a. 
SAHLINS, M. O pessimismo sentimental e a experiência etnográfica: por que a cultura não é um objeto em via de extinção (parte II). Mana. Rio de Janeiro, v. 3, n. 2, p. 103-150, 1997b.

SALTALAMACCHIA, N.; TICKNER, A. B. Introducción: una visión alternativa del espacio y los atores interamericanos. In: PISANI, F. et al. (Org.). Redes transnacionales en la Cuenca de los Hurracanes: un aporté a los estudios interamericanos. México DF: Instituto Tecnológico Autónomo de México/Miguel Ângel Porrúa, 2007. p. 7-25.

SANCHIS, P. Para não dizer que não falei de sincretismo. Comunicações do ISER, v. 45, p. 4-11, 1994.

SEGATO, R. L. La Nación y sus Otros: raza, etnicidad y diversidad religiosa en tiempos de Política de la Identidad. Buenos Aires: Prometeo, 2007.

SMITH, M. P.; GUARNIZO, L. E. The locations of transnationalism. Comparative Urban and Community Research, p. 3-34, 1998.

STEIL, C. A. Os demônios geracionais. A herança dos antepassados na determinação das escolhas e das trajetórias pessoais. In: DUARTE, L. F. D. et al. (Org.). Família e religião. Rio de Janeiro: Contra Capa, 2006. p. 219-239.

STOCKING Jr., G. W. Race, culture and evolution. Chicago: Chicago University Press, 1982.

STRATHERN, M. Cutting the network. The Journal of the Royal Anthropological Institute, v. 2, n. 3, p. 517-535, 1996.

SYNAN, V. El siglo pentecostal: un panorama general. In: SYNAN, V. (Org.). El siglo del Espiritu Santo: cien años de renuevo pentecostal y carismatico. Buenos Aires: Peniel, 2005. p. 11-24.

URRY, J. Small worlds and the 'new social physics'. Global Networks, v. 4, n. 2, p. 109-130, 2004. 